\title{
Prosthetic Rehabilitation in the Lower Limb
}

\author{
Bernard O'Keeffe ${ }^{1}$ Shraddha Rout ${ }^{1}$ \\ ${ }^{1}$ Otto Bock Health Care India, Mumbai, Maharashtra, India
}

\begin{abstract}
Address for correspondence Bernard O'Keeffe, BSc Prosthetics, Otto Bock Health Care India, 1st Floor, Vikas Centre, Dr. C. G. Road, Chembur East, Mumbai 400074, Maharashtra, India (e-mail: bernard.okeeffe@indiaottobock.com).
\end{abstract}

\begin{abstract}
Keywords

- lower limb amputations

- prosthetics

- leg prosthetics

- considerations before amputations

Lower limb amputations form a considerable number with 5,436,000 Indians having locomotor disability. Most members of this group are young, active earning males. The major cause of amputation is trauma. Hence, this population must be rehabilitated with priority, and best concerted efforts must be made by the medical community. In this article, the authors present available modern technologies in India and share best practices from their experience of treating Indian amputees for the past 20 years. The objective is to demonstrate to the medical community the optimal outcomes that can be achieved and help them make correct decisions on behalf of patients and their families. The article discusses history of prostheses, how to select optimal amputation level, preamputation preparation, determinants of good outcomes, preprosthetic preparation, components of prosthesis, their function and significance, rehabilitation process and guidelines, prescription criteria, and also special considerations such as multiple amputees or children.
\end{abstract}

\section{Introduction}

Data from Census $2011^{1}$ state that there are 5,436,000 people with locomotor disabilities in India. Unfortunately, there is little data available on the number of amputees in India. Nevertheless, as a medical community, it is extremely important to put in our best efforts to rehabilitate this subset of patients for social reasons. The major cause for amputations in India is trauma. ${ }^{2}$ It is known that trauma disproportionately affects young, economically active, male individuals who have a significant lifespan ahead of them. Successfully rehabilitated, these young amputees have a potential to become contributing, happy members of our society.

This article is our effort to present best possible solutions currently available for lower limb amputees and highlight how incorporating these solutions in the rehabilitation plan can help enhance quality of life for these amputees and, effectively, those of the families dependent on them.

\section{Brief History}

History of artificial limbs for the lower extremity is extremely interesting and often intertwined with the history of war and of surgery.

The first established example of a prosthesis is the Egyptian noblewoman's toe dating back to 950-710 BC.

published online

April 29, 2019

DOI https://doi.org/

10.1055/s-0039-1687919

ISSN 0970-0358.
Although the wooden toe offered no function, it possibly made the noblewoman "complete," by allowing her to wear an Egyptian sandal. Metal hooks and wooden pegs crafted by artisans-which seem as mere exaggerations today-were a reality for many centuries later.

The major advances in amputation surgery as well as prosthetic technology came during or after the American Civil War (1861-1865). ${ }^{3}$ Use of ether or chloroform for anesthesia, use of bromine to prevent gangrene, allowing only experienced surgeons to perform amputations, mass casualty management systems-these and many more techniques reduced mortality. However, soldiers who survived-many of them amputated-had to be rehabilitated. In Europe and in USA, many entrepreneurs designed newer types of prosthetic components as well as suspension techniques benefitting amputees ( - Fig. $\mathbf{1}$ ).

The World War I saw the need for providing prostheses to war amputees quickly, especially in Germany. German technician Otto Bock started serial production of prosthetic components, eliminating the need to handcraft individual components, reducing rehabilitation time ( - Fig. 1 ). As wood was beginning to become scarce, newer materials such as plastics were now used as substitutes.

In 1915, the first pneumatically powered hand was introduced in Germany. ${ }^{4}$ Pneumatics and, eventually, 


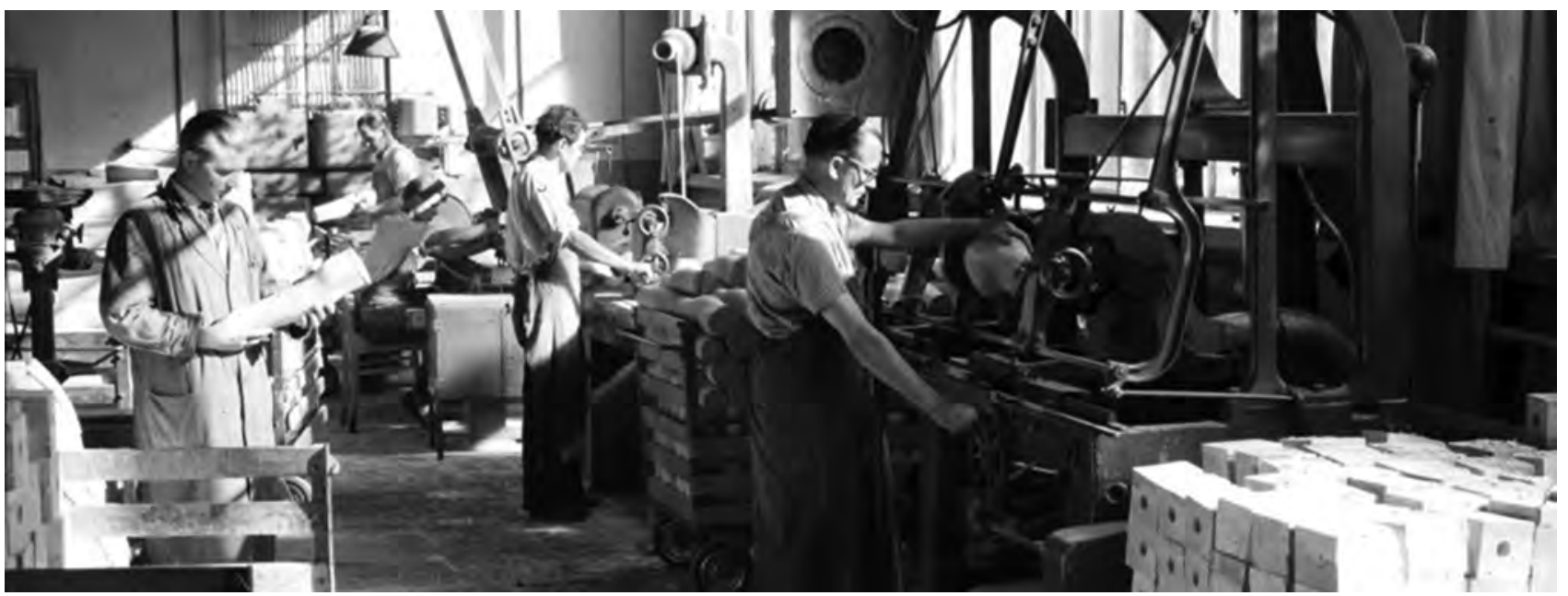

Fig. 1 Components of artificial limbs are being mass-produced in a factory.

hydraulics found their way into lower limb prosthetics as well. However, the key milestone in the history of leg prosthetics was introduction of the C-leg in 1999-the first fully microprocessor-controlled prosthetic knee. Clinically proven to reduce falls, C-leg today has become a standard of care for above-knee amputees ${ }^{5}$ and can be seen being used by several Indian amputees as well.

Iraq and Afghanistan conflicts also saw a large number of young soldiers being severely injured due to the new devastating weaponry, yet surviving due to advanced evacuation techniques. These amputees did not want to be pushed back to "desk jobs" but wanted to get back to service, even to active combat. The Genium X3 was a result of R\&D from the U.S. Army, which allowed these veterans to run, climb stairs one over one, perform activities in or even under water, and go back to active service ${ }^{6}$ ( Fig. 2 ).
The first Paralympic games were held at Rome in 1960. Since then, Paralympic movement has inspired thousands of disabled athletes and other amputees to participate in sports and has introduced improved prosthetic designs exclusively for sport use.

Currently for prosthetic rehabilitation, advanced components and techniques are available and accessible. Correct, usable information about the available choices and processes can help the teams guide the patient and family appropriately. Great outcomes could be achieved if the surgical team intervenes and helps the patient and family make a reliable choice of a skilled and experienced service provider as well as an appropriate prosthetic solution.

This is just to reiterate the African proverb that says, "If you want to go faster, go alone. If you want to go longer, go together!"

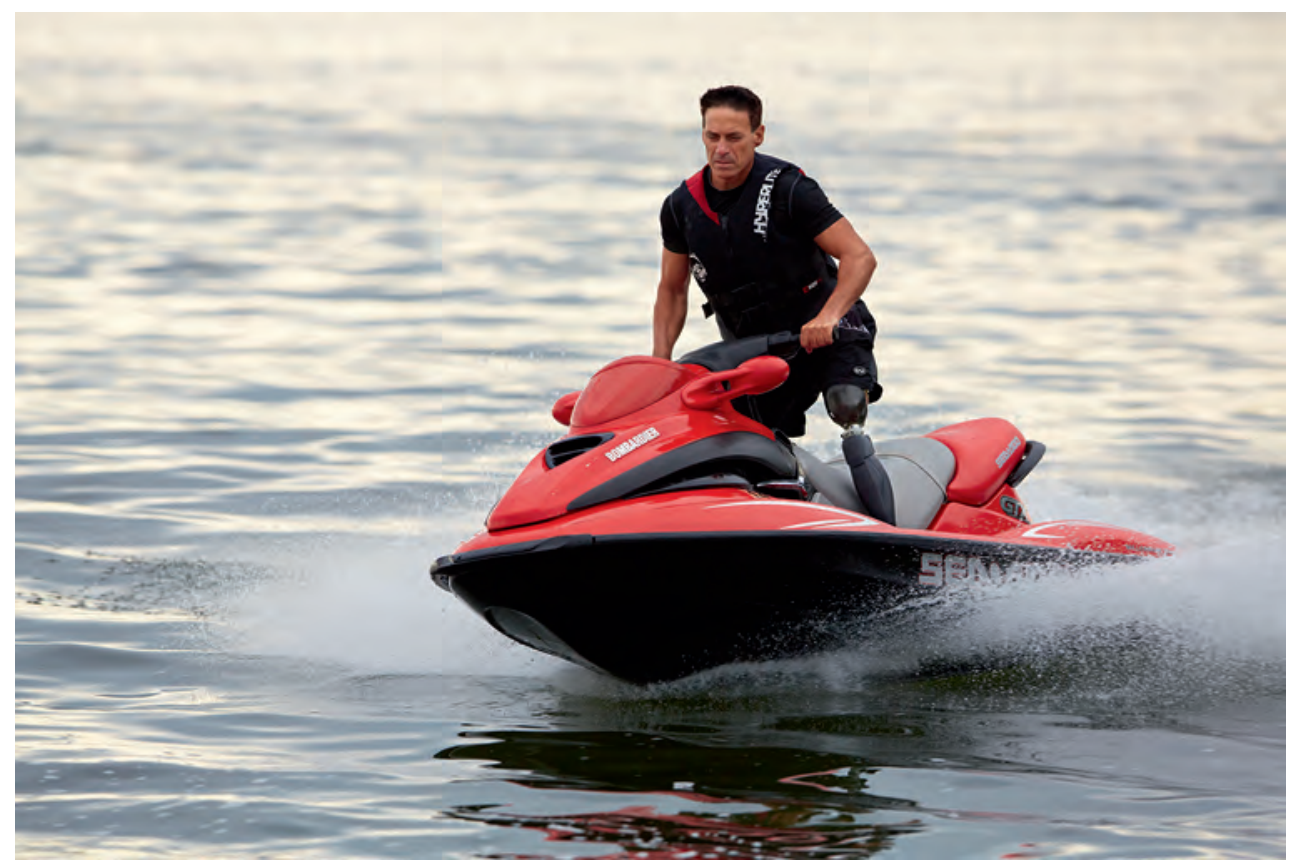

Fig. 2 An American war amputee from 2002 was medically cleared return to flying status in June 2007 with his microprocessor-controlled transfemoral prosthesis. 


\section{Selection of Amputation Level}

Several assessment scores are available to help surgeons make "salvage or amputation" decision. ${ }^{7}$ Hence, we will not elaborate on tools to make this decision.

However, with our 20 years of experience in treating Indian amputees, we wish to outline certain insights that can assist during amputation decision.

The obvious principles here include (1) preserve as many joints as possible and (2) preserve maximum possible bone length.

A study evaluating 28 transtibial (TT) amputees for their functional mobility concluded that the amputation technique and resulting residual-limb factors may be important for patients to achieve functional prosthetic use. ${ }^{8}$

Ideally, a residual limb length of less than $5 \mathrm{~cm}$ in

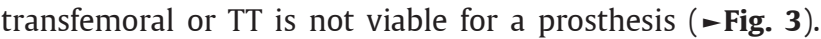
However, we recommend that the decision to choose the next higher amputation level be made in consultation with an experienced prosthetist. For example, in a TT residual limb, length less than $5 \mathrm{~cm}$ is short per say, but if reasonable range of motion (ROM) is available at the knee, it is preferred over a transfemoral amputation. With advanced prosthetic suspension techniques, the patient can still achieve an outcome that may be considered suboptimal for a TT amputee but still will be better than that for a transfemoral amputee!

Another perspective to take note of is that longest possible may not always be ideal. If the available clearance (distance between the end of residual limb from ground or from the next higher joint) is very limited, special components built to be of low height need to be used. This may compromise function and add unnecessary costs. We will like to share an example of a knee disarticulation amputee for whom kneeling in prayer is crucial to follow his religious beliefs.
In his case, the prosthetist will not be able to use a "rotation joint"-an accessory that allows the lower segment to rotate and clear way for kneeling-as it makes the prosthetic thigh longer than the normal thigh. This may keep the person away from achieving "complete" rehabilitation. Therefore in this case, a transfemoral amputation could have been considered.

Pain on weight-bearing, limited, or no ROM at the proximal joint and very short bony and muscular lever arms are the indicators to consider a proximal level of amputation ( - Fig. 4).

Transfemoral versus knee disarticulation has been a long-standing debate. Once again, the decision must be made based on individual patient situation and, preferably, in consultation with an experienced prosthetist. We have put together a comparison of advantages and disadvantages of knee disarticulation amputation over a transfemoral one in - Table 1 .

\section{Preamputation Preparation}

The key determinant of success in prosthetic rehabilitation is the surgeon's approach toward amputation. Instead of considering amputation as a failure to save the limb, if it is viewed as a preparation for patient's mobility and independence, the same attitude can translate to all other medical and paramedical team members, including the patient and the family.

Preempting the patient about "what lies ahead" is also equally important. The patient/his family may not be aware about modern prosthetic options and outcomes that can be achieved. We recommend that an experienced prosthetist should conduct preamputation counseling, using realistic outcome videos or peer interactions. This can bring the patient and the caregivers into the right frame of mind and help them optimally utilize the time until prosthetic fitment begins.

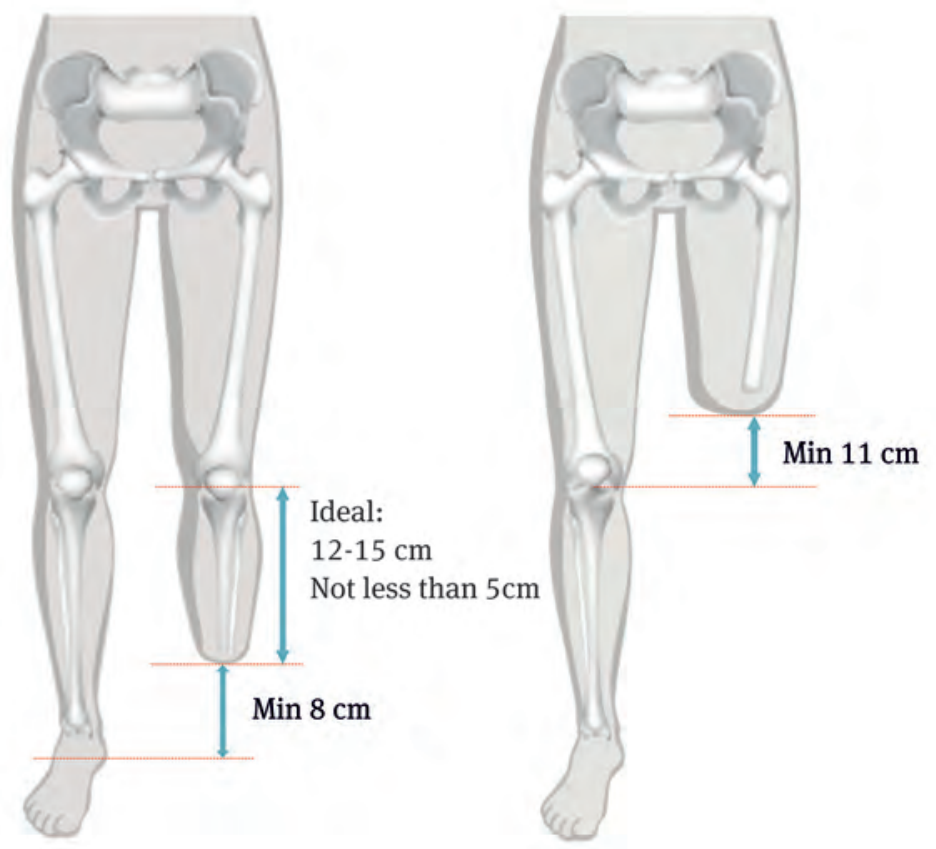

Fig. 3 Ideal residual limb lengths. 

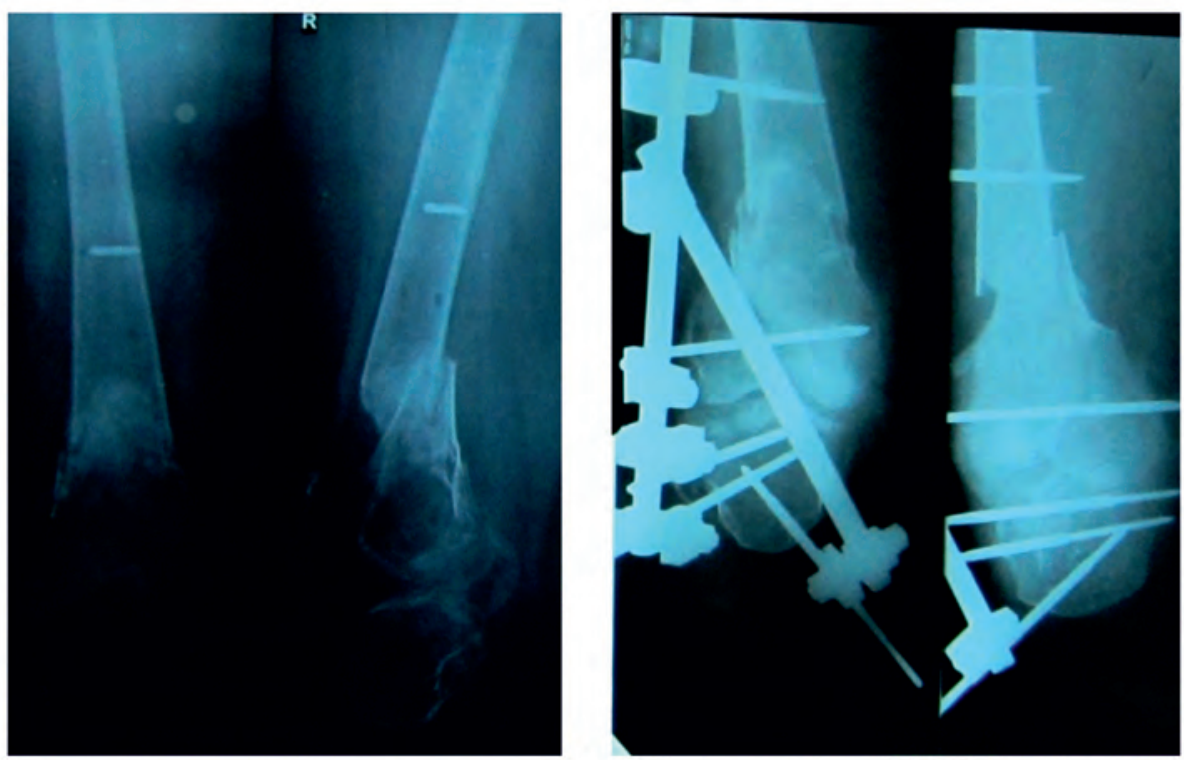

Fig. 4 Examples of when a proximal amputation could have been a better choice rather than "preserving" what was available.

Table 1 Knee disarticulation amputation-advantages and disadvantages

\begin{tabular}{|l|l|}
\hline For & Against \\
\hline Lower infection rates $^{9}$ & $\begin{array}{l}\text { Cosmetically less appealing due } \\
\text { to bulbous residual limb end }\end{array}$ \\
\hline $\begin{array}{l}\text { Preserves the epiphy- } \\
\text { seal growth plates in } \\
\text { children }\end{array}$ & $\begin{array}{l}\text { Cosmesis compromised if the } \\
\text { prosthetic thigh is longer than } \\
\text { the normal thigh, especially } \\
\text { while sitting }\end{array}$ \\
\hline $\begin{array}{l}\text { Better sitting balance in } \\
\text { case of nonambulatory, } \\
\text { bilateral cases }\end{array}$ & $\begin{array}{l}\text { Limits the choice of prosthetic } \\
\text { joints that can be used }\end{array}$ \\
\hline $\begin{array}{l}\text { Lower metabolic costs, } \\
\text { better walking speeds }\end{array}$ & \\
\hline $\begin{array}{l}\text { Better suspension, } \\
\text { hence better control } \\
\text { over the prosthesis }\end{array}$ & \\
\hline $\begin{array}{l}\text { Easier to don and doff, } \\
\text { ability to use for a lon- } \\
\text { ger time }\end{array}$ & \\
\hline $\begin{array}{l}\text { Superior performance } \\
\text { in sports }\end{array}$ & \\
\hline
\end{tabular}

\section{Amputation Techniques and Predictors of Rehabilitation Outcomes}

Various amputation techniques are sufficiently described in the clinical literature elsewhere and hence elaborate description to be out of the scope of this article.

However, we want to draw attention to residual limb-related criteria that directly link to successful rehabilitation as described by Chakrabarty. ${ }^{12}$ Chakrabarty rated residual limbs of 132 unilateral TT and transfemoral amputees on the following criteria, arriving at one overall score for each patient. The maximum score that could be achieved was 100 .

1. Wound

2. Edema

3. Scar

4. Skin

5. Length

6. Shape

7. Tenderness

8. Proximal joint contracture

9. Bone end sculpted (and covered)

10. Dog ears

11. Redundant tissue

12. Additional scars/other factors

Scores $>60$ directly linked to improved outcomes.

The authors opine that it will be a good practice to document quality of stump and correlate with prosthetic outcomes later.

\section{Preprosthetic Preparation}

Following discharge from the hospital, prosthetic fitment commences not before 6 to 8 weeks after amputation, even later for dysvascular amputees. It is common for patients to not undergo physiotherapy, not follow correct positioning techniques and nutrition, eventually ending up with reduced ROM or even contractures and poor strength and balance. This delays the prosthetic rehabilitation and contributes to suboptimal outcomes. To avoid this, the authors recommend the following postoperative, preprosthetic protocol that they have been using successfully. 
1. Edema therapy: Gentle bandaging can normally start on day 1 . The residual limb should be positioned above heart level to encourage a good venous return.

2. Correct patient and stump positioning (-Fig. 5): Passing on instructions to the patient and caregivers to be followed after discharge is crucial. The patient must maintain the residual limb straight, without using any pillows under the joint. Lying flat on belly with head away from amputation side for at least $30 \mathrm{~min} /$ day will help reduce flexion tendency. While sitting on a wheelchair, a flat plank must be used underneath the residual limb, instead of leaving it hanging with knee flexed. If not followed correctly, the patient may end up with a contracture by the time he presents for prosthetic fitting.

3. Mobilization: The residual limb and other joints should be moved several times a day. The patient can be encouraged to sit on a chair without a back support.

4. Stump shaping/bandaging: The patient and family must be trained on use of crepe bandaging or stump shrinkers. They must also be instructed to visually examine for any redness or discoloration after the bandage is removed.

5. Muscular training: Often with prolonged illness or hospitalization, the patient has overall weakness and balance issues. The time between discharge and start of prosthetic fitment can be effectively utilized to overcome this. The therapist can work on trunk strengthening, intact limb strengthening, and muscle strengthening for the residual limb among other things.

6. Scar treatment and skin preparation: In the authors' experience, adherent, immobile scars and pain/sensitivity at the site of scar interferes with prosthetic fittings. Textured objects such as Turkish towel, soft brush, beans, rice, and straw are used for desensitization. Massage starting from scar upward. Apply prescribed antiseptics and moisturizers.

7. Stump hygiene: The patient and caregivers must be instructed on appropriate skin care-washing with clean water and unscented soap after the wound is appropriately healed and drying thoroughly with a clean dry towel.

\section{Components of Prostheses}

Discussion of detailed componentry used in a prosthetic limb is out of scope for this article. However, we describe key parts of the prosthesis (-Fig. 6) and their functions so that the readers can help their patients make useful prescription choices:

1. Interface materials/socket liners: New materials and developments in interface technologies offer a world of benefits to prosthetic patients. Old generation of prostheses were directly applied on skin, creating abrasions, excessive sweating, and eventually affecting user compliance. Residual limb liners made of new materials-foams, gels, especially silicone gels-make wearing a prosthesis comfortable. Even for traumatic cases with poor skin conditions or dysvascular patients, silicone, polyurethane, and copolymer gel liners offer great protection, leading to increased time of prosthetic usage.

2. Prosthetic socket: This is the customized part of the prosthesis that is crucial to prosthetic performance. The socket should offer comfort and grip the residual limb in all stages of walking and other activities. Socket designs and suspension techniques are determined based on patient's residual limb conditions and other patient factors. For example, for a dysvascular TT amputee, a socket with a gel liner offering total surface weight-bearing (TSWB) design and vacuum-based suspension is advantageous ${ }^{13}$ versus

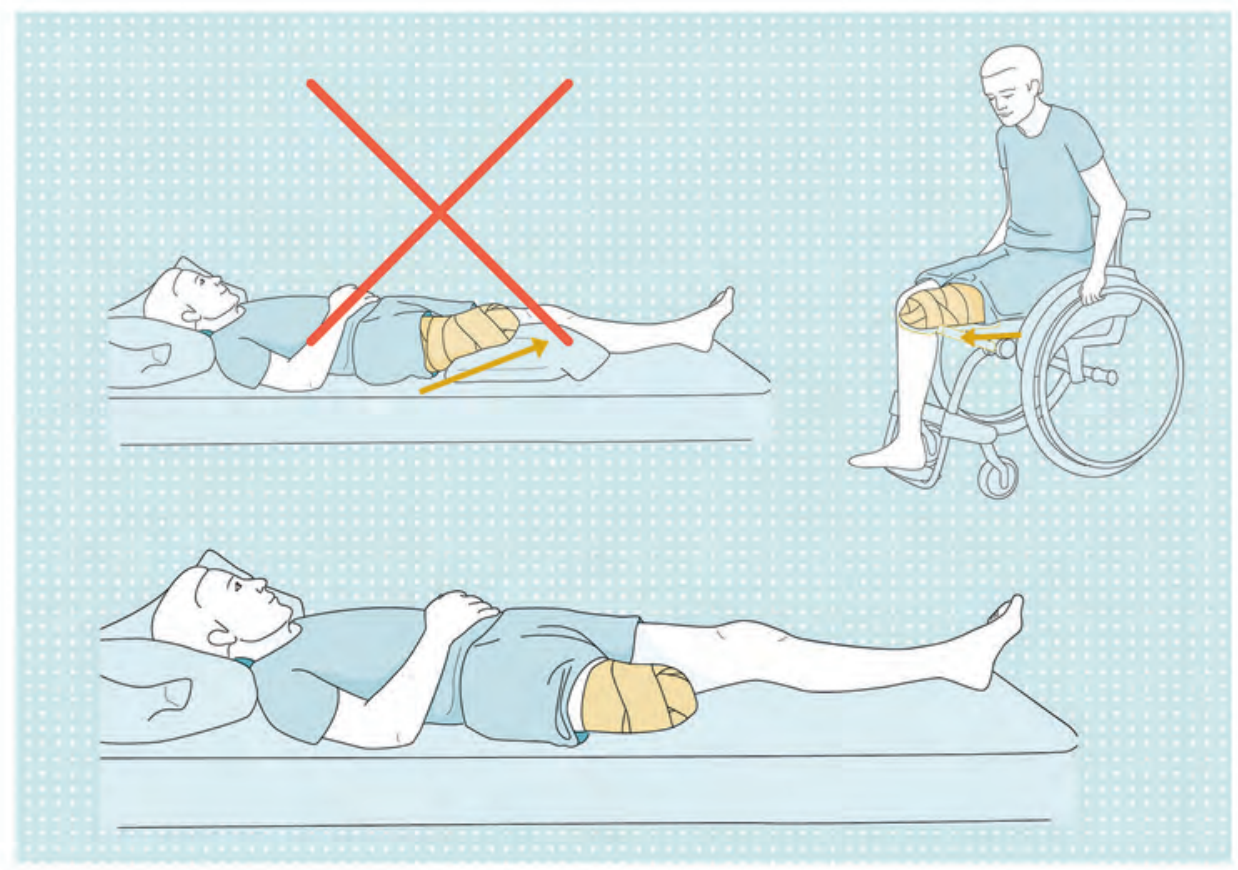

Fig. 5 Positioning after amputation. 


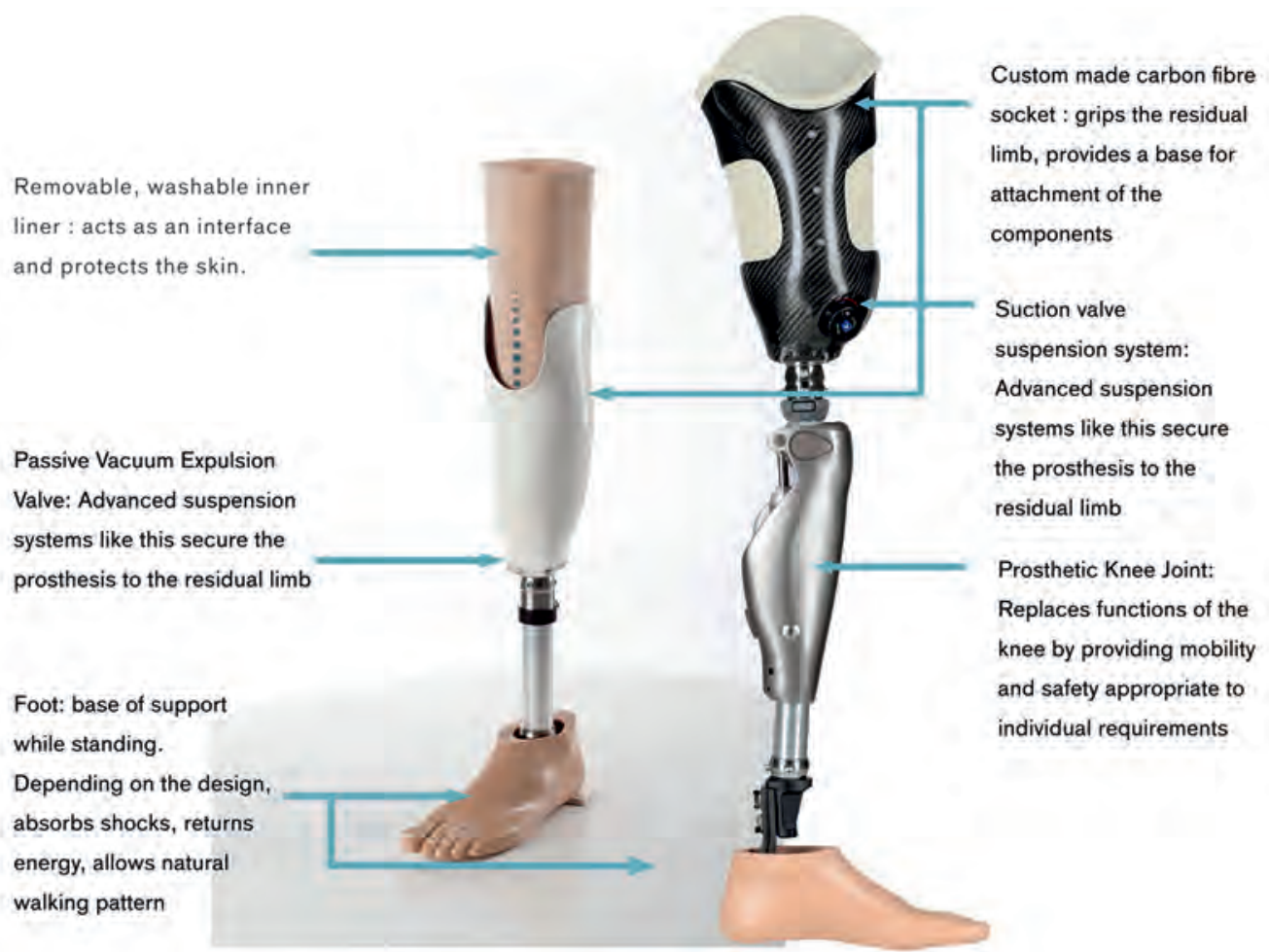

Fig. 6 Key parts of below- and above-knee prostheses.

one with foam liner and specific/patellar tendon weight bearing (PTB). The latter may cause uneven distribution of weight leading to skin breakdowns. The fitting prosthetist's skill and experience is as much a decisive factor in designing a good fitting socket as an operating surgeon's skill and experience in performing a successful amputation.

3. Prosthetic knee joints: For transfemoral, knee disarticulation, and hip disarticulation amputations, various types of prosthetic knees are available. While prescribing, two main functions need to be considered-stance control (safety while standing and mid-stance stage of gait) and swing control (ability to swing the knee-foot segment of the prosthesis to clear ground during swing phase of gait). In older amputees, safety offered by the knee joint is a key criterion. At the same time, the knee joint must minimize energy cost of walking, must be lightweight, offer physiologic gait, etc. In younger, more active amputees, higher knee joint function in terms of different walking speeds, ability to manage slopes and steps, reliability of construction, etc. is expected.

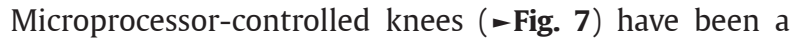
game changer in prosthetics since their launch in $1999 .{ }^{14} \mathrm{~A}$ set of sensors give feedback about knee joint position in space, speed, direction of movement, etc. to a microprocessor that

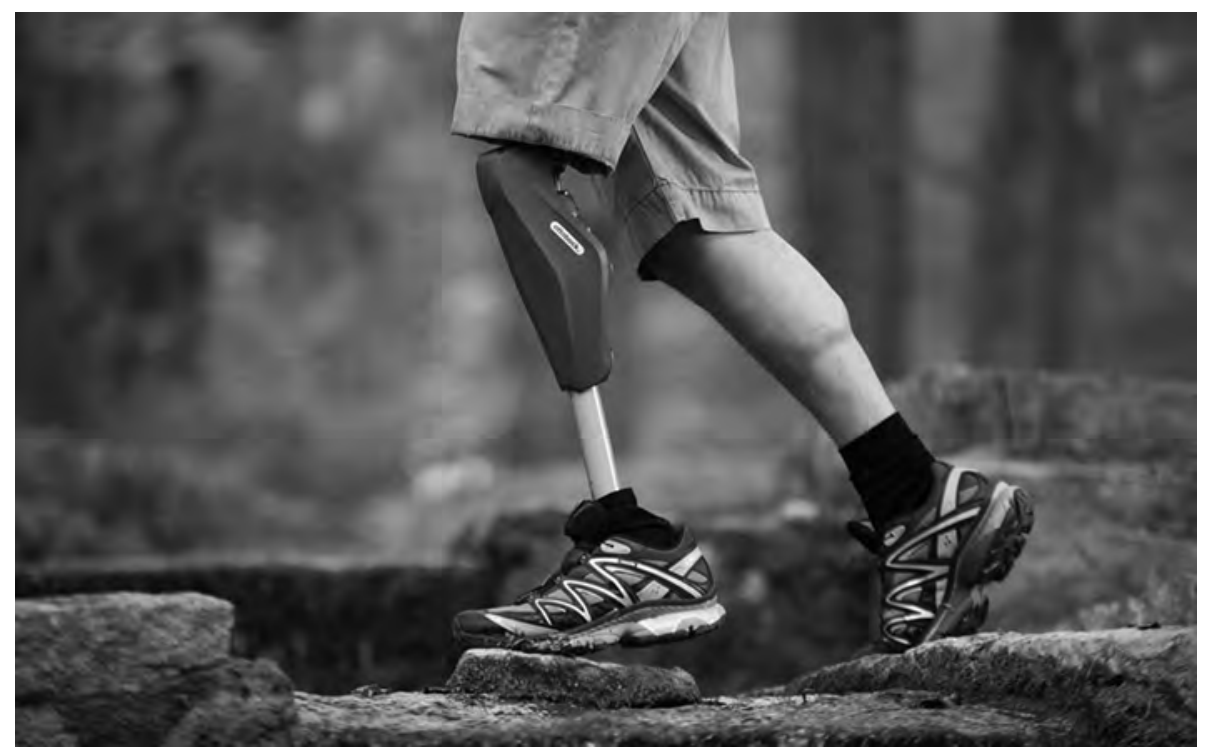

Fig. 7 The Genium microprocessor-controlled knee offers excellent safety even on difficult terrains. 
stores thousands of gait algorithms. The microprocessor then defines the situation-user is changing speed/falling/getting down the slopes/sitting in a chair-and controls the hydraulic resistance of the knee joint accordingly. The hydraulic resistance adjustment leads to either increased speed of swing or makes knee flexion very difficult. This allows the user the time to shift balance to intact foot avoiding a fall. Making the knee flexion slightly difficult can allow safe getting down the slopes. Whereas, no resistance at the knee can allow comfortable sitting on the chair.

The MPK technology is not new to India anymore, and several amputees today are enjoying higher safety and higher function offered by it.

4. Prosthetic feet: Feet absorb shocks at heel strike, stabilize the prosthesis during stance phase of gait, and then smoothly roll over and propel the body forward by pushing the ground behind. Amputees of different mobility grades require these functions in different amounts. Choosing a foot wisely can make a great impact on the prosthetic outcome. The newer designs of feet are mostly made of carbon fiber and offer dynamic function. In older amputees, however, stability offered by the foot is also equally important.

Microprocessor technology has also made its headway in feet. The benefits of microprocessor feet and ankles are the ability to lift the forefoot during ground clearance, avoiding falls, safety especially on uneven terrain, and reduced peak pressures on the residual limb. ${ }^{15}$

5. Functional adaptors: Specific functions required during an amputee's everyday activity are performed by functional adaptors. A rotation joint ( - Fig. 8) may offer knee rotation, making it easy to wear and remove shoes, whereas a torsion adaptor may ease the residual limb of stress in turning round as in swinging in cricket/golf. These accessories are always optional and can be chosen

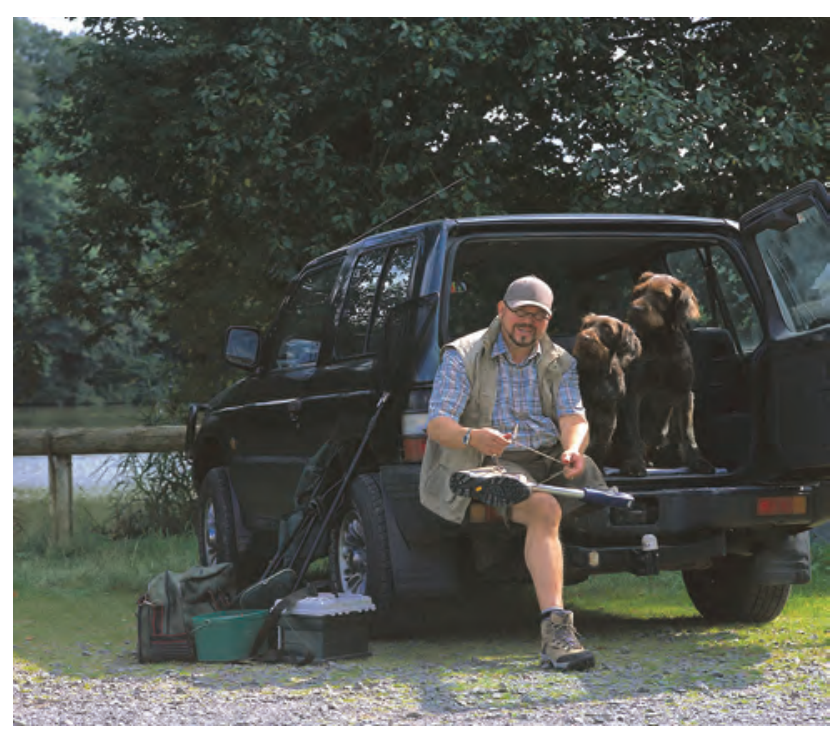

Fig 8 A transfemoral amputee uses a rotation joint for comfortable sitting. to be a part of the prescription after assessing individual activities of daily living (ADL) needs.

\section{Rehabilitation Process and Timelines}

Although rehabilitation starts immediately after the amputation, it is a continuous process for prosthetic service providers. Prosthetic fitting can start as soon as surgical wounds are sufficiently healed, normally within 6 to 8 weeks of amputation, with exceptions for dysvascular or multitrauma patients. Then on, initial prosthetic fitting and training may take 2 weeks. However, the real challenge starts only when the patient is fitted with the prosthesis and starts reintegration into his daily life. It is most important for the prosthetic service provider to work closely with the patient and therapist to resolve challenges of daily living. There may be a particularly steep slope to be encountered on the patient's way to workplace or a particular height of the sitting chair. Together, the prosthetist and the patient should be able to adjust the functions offered by the prosthesis to fulfill user requirements. Regular follow-ups and ongoing resetting of rehabilitation goals are very important.

With time and usage, the residual limb shrinks. The socket and the prosthesis may need readjustments until the residual limb volume stabilizes sufficiently. With modular components being in use today, only the socket part can be changed, without having to change the rest of the components.

A prosthesis may last for 5 to 7 years typically under Indian conditions, with intermittent requirement of change of consumables-socks, straps, liners, etc. However, at the time of upgradation or change, users' changed activity level and requirements from the prosthesis must be reviewed.

\section{Prescription Criteria}

It is important that a prosthesis be functional as well as economical, matching the amputee's requirements.

The authors use a functional classification based on activity levels to determine needs of the amputee and then select components to provide function accordingly. These activity levels are described in - Table 2 .

\section{Special Considerations-Children, Multiple Amputations, Sports}

Children are special. Their rehabilitation requirements are different from those of an adult. Children's prostheses must allow some kind of growth adjustments. Children are extremely active, so the componentry used must be robust; at the same time, follow-up and repair services must be reliably available. Among the "soft factors" of treatment, the prosthesis as well as the fitting process must be enjoyable for the child to get her to use the prosthesis. The objective of treatment here should be to allow the child to fully reintegrate into her routine activity-schooling, cycling, and playing football. Only then we will be able to help the child to grow up without complexes and inhibitions into a happy individual. 


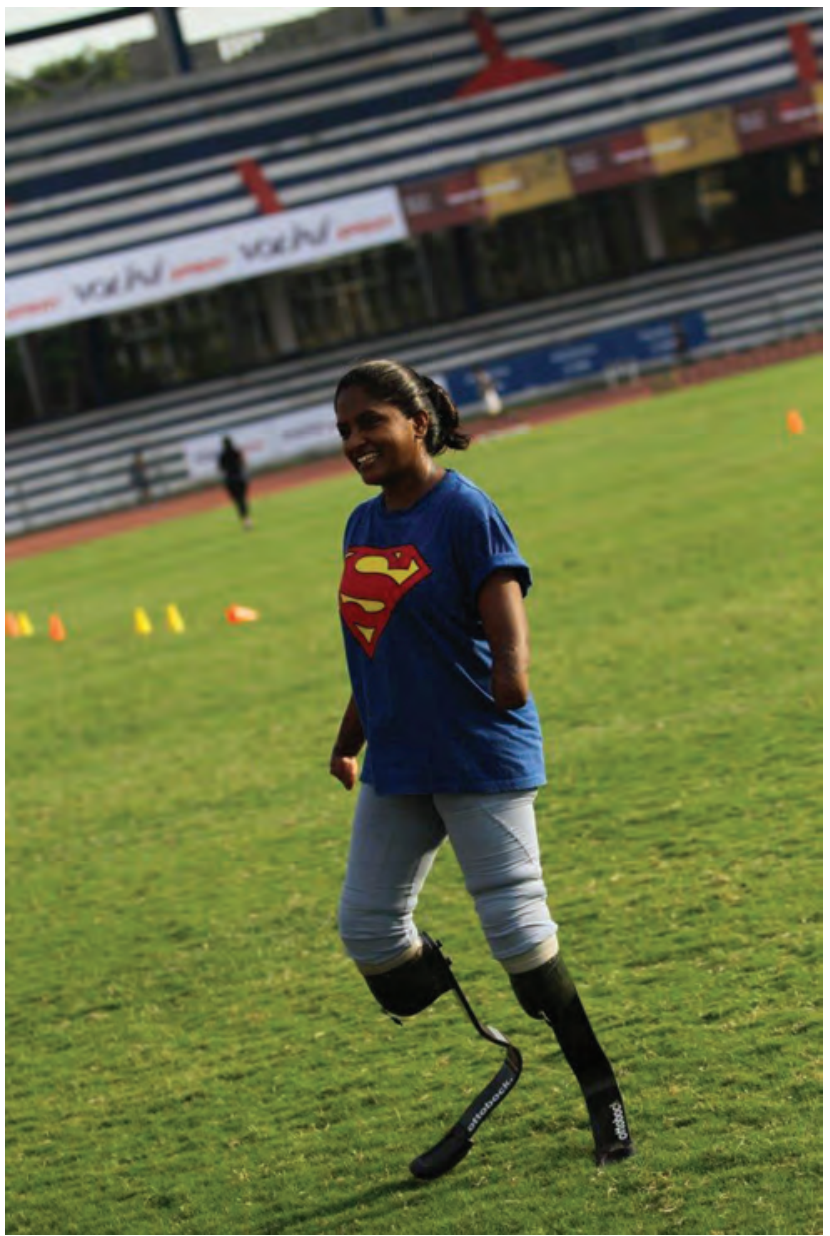

Fig. 9 A four-limb amputee determinedly uses her running blades to compete in marathons.

Multiple amputations are not uncommon in India, where trauma is a major cause of amputation. Therapy and ADL training play a very important role in rehabilitating multiple amputees. Most advanced prosthetic componentry may not be utilized to the fullest if the patient has poor trunk musculature. The energy cost of walking is high in such cases, and there are chances that the patient may settle down to wheelchair mobility if he/she gets tired quickly. The choice of an appropriate prosthetic service provider experienced in treating multiple amputees becomes a key determinant of successful rehabilitation ( - Fig. 9).
Sport is essential for life-especially for amputees. It can help fight stresses that disability brings along. Sport can also help amputees delay lifestyle-related issues such as early osteoarthritis and back pain. Prostheses for sports have different functional requirements from those used in daily life. They have to be robust to absorb shocks and extremely dynamic. Carbon fiber is the material of choice when it comes to sport feet design.

\section{Outcome Measurements}

Measuring and documenting prosthetic outcomes have recently picked up speed in the developed world where most treatments are paid for by the government or insurance. In India, however, this practice is almost nonexistent.

The authors routinely use outcome measures in their clinical practice (-Fig. 10). The patients are evaluated pre-fitting, post-fitting, at 2 to 3 weeks follow-up, and then ongoing follow ups. The questionnaire is a mix of self-reported qualitative questionnaire and performance-based tests such as time-up and go (TUG), four square step, and 6-minute walk. The data are stored at a central server. Analysis can be made by comparing socket comfort, pain, time taken to complete four square step test (dynamic balance), and distance covered in the 6-minute walk test over follow-up intervals.

According to us, this holds great potential for objectively analyzing benefits of treatments, for which most of the times amputees pay from their own pockets.

\section{Summary}

Prosthetic service provision is at a very interesting turn in history. New, modern components and techniques are available, but experienced, mature clinicians to apply them are scarce. Right from decision to amputate to the choice of an appropriate prosthetic prescription, the decision is a major one with a lot at stake. Often, patients and families are in a vulnerable emotional and financial state at this stage. Correct direction from the surgical team may help the patient and families choose the right service provider and, ultimately, be optimally rehabilitated and fully integrated in the society.

Table 2 Activity level assessment to determine prosthetic needs of the amputee

\begin{tabular}{|l|l|l|l|}
\hline Mobility grade & Limited mobility & Everyday life & Active life \\
\hline $\begin{array}{l}\text { Prosthetic } \\
\text { usage }\end{array}$ & $\begin{array}{l}\text { Mostly indoor usage, with/ } \\
\text { without a walking aid. One } \\
\text { consistent walking speed }\end{array}$ & $\begin{array}{l}\text { Indoor as well as outdoor usage, without } \\
\text { walking aid. Occasional leisure sport activity, } \\
\text { two or three different walking speeds }\end{array}$ & $\begin{array}{l}\text { Active usage on uneven terrain, use } \\
\text { of different walking speeds during the } \\
\text { day, frequent leisure sport activity }\end{array}$ \\
\hline $\begin{array}{l}\text { Requirements } \\
\text { from the } \\
\text { prosthesis }\end{array}$ & $\begin{array}{l}\text { - Safety } \\
\text { - Low weight }\end{array}$ & $\begin{array}{l}\text { - Cosmesis } \\
\text { - Runction }\end{array}$ & - Function \\
Robustness \\
Energy return
\end{tabular}




\section{Individual Patient Report}

\section{Treatment Progress}

Mobility before and after treatment

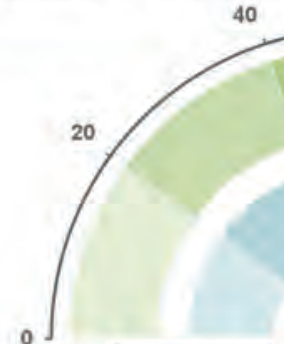

Pre-Fitting

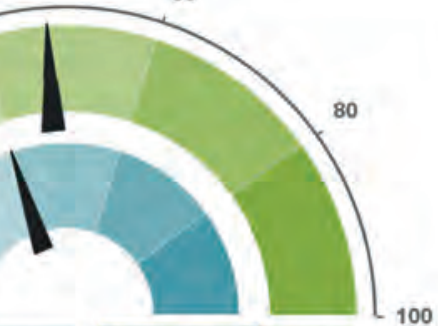

40
This speedometer shows the mobility on a rating scale from $0 \%$ to $100 \%$. The arrow indicates the patient's result based on the patient questionnaire before and after the treatment.

\section{Your level of balance}

Four step square test
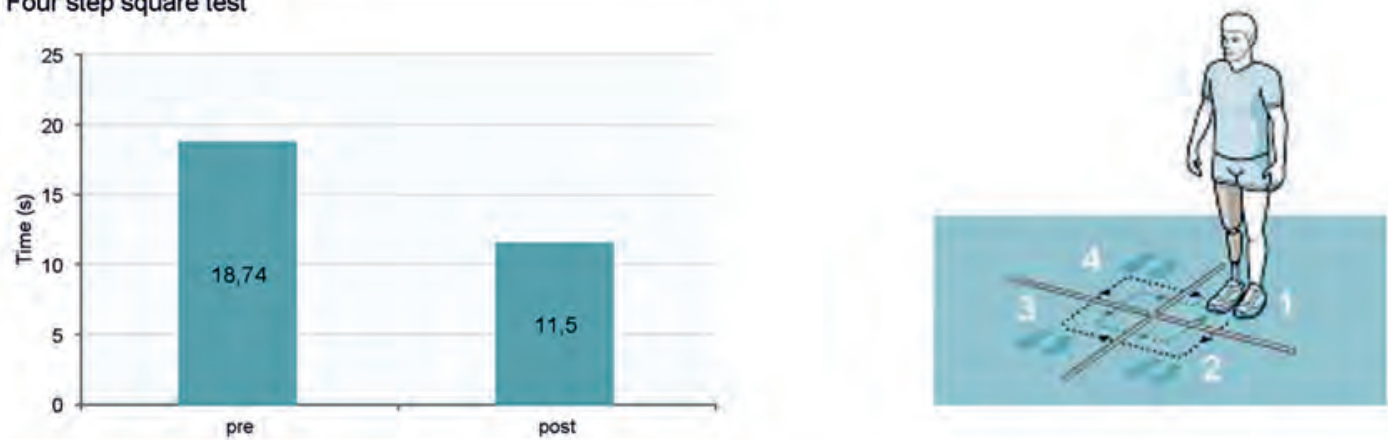

\section{Your level of endurance}

\section{6 minute walk test}
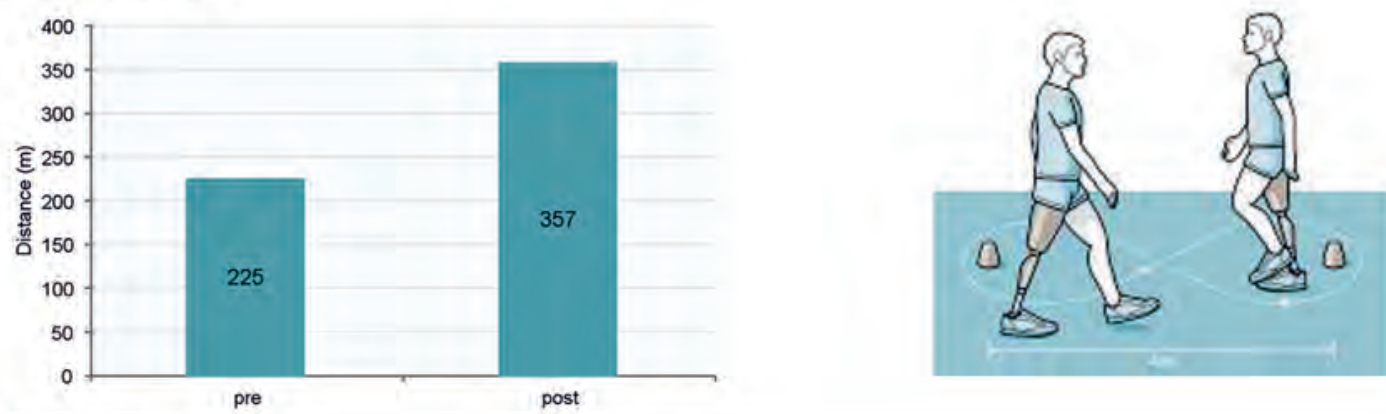

Comment space for clinician or using text blocks

Fig. 10 An indicative example of a treatment progress report of a lower limb amputee. 


\section{Conflict of Interest}

The author(s) are employed by Otto Bock Health Care India Pvt. Ltd.

\section{Fund source}

The author(s) received no specific funding for this work.

\section{References}

1 Census 2011. http://www.censusindia.gov.in/2011census/population_enumeration.html

2 Pooja DG, Sangeeta L. Prevalence and aetiology of amputation in Kolkata, India: a retrospective analysis. Hong Kong Physiother J 2013;31(1):36-40

3 Miller C, Finn A, Delzell E. Battlefield injuries: Saving lives and limbs throughout history. Lower Extremity Review Magazine. October 2013

4 Childress DS. Historical aspects of powered limb prostheses. Clin Prosthet Orthot 1985;9(1):2-13

5 Fairley M, Microprocessor-controlled knees: evolution of a game changer. The O\&P EDGE June 1, 2014

6 Cronk MT. New knee helps amputees return to front lines. DoD News January 10, 2012

7 Shanmuganathan R. The utility of scores in the decision to salvage or amputation in severely injured limbs. Indian $\mathrm{J}$ Orthop 2008;42(4):368-376
8 Arwert HJ, van Doorn-Loogman MH, Koning J, Terburg M, Rol M, Roebroeck ME. Residual-limb quality and functional mobility 1 year after transtibial amputation caused by vascular insufficiency. J Rehabil Res Dev 2007;44(5):717-722

9 Smith DG. the knee disarticulation: it's better when it's better and it's not when it's not. In Motion 2004;14(1)

10 Pinzur MS, Gold J, Schwartz D, Gross N. Energy demands for walking in dysvascular amputees as related to the level of amputation. Orthopedics 1992;15(9):1033-1036, discussion 1036-1037

11 Hagberg E, Berlin OK, Renström P. Function after throughknee compared with below-knee and above-knee amputation. Prosthet Orthot Int 1992;16(3):168-173

12 Chakrabarty BK. An audit of the quality of the stump and its relation to rehabilitation in lower limb amputees. Disablement Services Centre, Harold Wood Hospital, UK

13 Andrews LK, Bellmann M, Burger H, et al. ISPO Report-Lower Limb Amputations due to Vascular Disease: A Multidisciplinary Approach to Surgery and Rehabilitation

14 Fairley M. Microprocessor-controlled knees: evolution of a game changer. The O\&P Edge June 2014

15 Kaluf B, Smith C. Advantages and/or disadvantages of microprocessor controlled prosthetic feet and ankles. Congress Lecture [6802] 2018 